\section{Briminal Alrticleg.}

\section{THE SUTURE OF ARTERIES.}

HY J. C. HUBBARD, M.D., BOsToN,

Third Assistant Visiting Surgeon, Boston City IIospital; surgeon to Out Patients, Carney Hospital; Assistant Surgeon o Out Patients, Infants' Hospital.

THE suture of blood vessels is no new attempt of the surgeon to enter unexplored fields, for in 1762 Lambert put stitches into the artery of a horse, and at about the same time Hallowell sutured the brachial in man. The operation then fell into disrepute from the unsuccessful experiments of Assman in 1773. No more attempts were made till after the discovery of antiseptic methods, when in 1881 Czerny sutured the internal jugular vein in man. The suture was a success, though the patient died from other causes. From this beginning the repair of injuries to veins came to be more and more generally employed, until in 1892 Schede was able to report iwenty-five to thirty successful vein sutures of his own, including one of the inferior cava.

Meanwhile, however, the repair of arteries seems not to have been so generally attempted and little, comparatively, was done. This conservatism was due partly, without doubt. to the fear of the formation later of an aneurism at the site of the suture, or of an endarteritis with thrombosis, but principally to the failure of the experiments on animals carried out by Gluck in 1882 and Horoch in 1888. Gluck reported a series of nineteen failures due to uncontrollable bleeding from the stitch holes, and Horoch found in all his cases a thrombus filling the vessel at the region of the suture.

In 1889, however, Jassinowsky published a series of successful experiments, proving the fears of the older surgeons completely groundless. It seems to be due to his work that the operation has been brought out of disfavor, for his experiments were carried out most satisfactorily. His animals were killed at varying intervals from one hour to one hundred days after the operation, and some of the specimens were examined microscopically. In all his cases but one the lumen of the vessel was open. In this one the wound about the vessel was septic and a thrombus partially occluded the artery. In none of the cases was there any tendency to the formation of an aneurism. On the contrary, the vessel wall was thickened and in some the lumen was somewhat narrowed.

He formulated a few rules, following which would ensure a successful result. The wound in the vessel wall must be smooth, not bruised or covered with adherent clots; the suture must pass through only the adventitia and media, and any bleeding through the stitch holes must be controlled by pressure for a few moments.

The next great step was made by Murphy in 1897, who found by experimentation that when

1 Read before the Surgical Section of the Suffolk Diatrict MedIoal Boclety, Jan. 8, 1402. an artery is cut more than one-half across it is best to adopt his invagination method (which I will describe later) and not try to suture it, for in a cut of such magnitude the vasa vasorum are so destroyed that there is fear of slight necrosis of the vessel wall and secondary hemorrhage. Under such circumstances he resects that bit of the artery and invaginates the proxinal into the distal portion.

His nethod is as follows: Two or three doubleheaded sutures are inserted into the proximal portion, including only the two outer coats of the artery. These are then reinserted at regular intervals, one-third to one-half of an inch above the end of the distal portion, from within outward. The threads are then tied, invaginating the artery as they are pulled tight. In order to facilitate the invagination, a small incision, from one-third to one-fourth of an inch in length, is made, par-

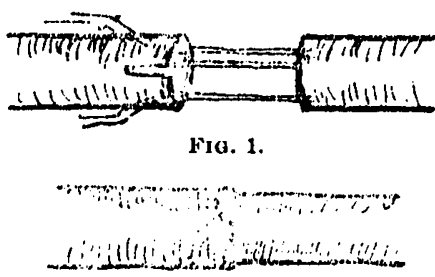

FIG. 2.

Muridiy's Invagination Methon.

F1o, 1. First step in operation. Fo. 2. Completed operation.

allel to the long axis of the vessel. Four or five interrupted sutures are then inserted into the intussuscipiens, binding it to the surface of the intussusceptum, the sutures in the latter including only the adventitia and media. By this method a large surface contact of the vessel wall is secured, ensuring a more safe healing and less chance of hemorrhage, as the greater the arterial pressure the closer pressed together are the vessel walls. He reports a number of experiments and two actual cases.

Dörfler then took up the subject, with the hopes of deciding some of the disputed questions as to the best suture material and method of controlling the circulation during the operation, etc. He thoroughly, it seems to me, worked out their answers. Before his experiments, everyone had felt it very necessary not to injure the intima by the clamps or ligatures which control the circulation during the operation, feeling that a thrombus was sure to form at the site of the injury. Dürtler showed that it was safer to control the circulation with such light pressure, that the intima could not be injured, and also that a bruise or tear of the lining coat would not necessarily cause the formation of a thrombus. In other words, an injury to the intima is of no consequence in itself, but that interference with the circulation and infection are the principal causes of trouble, and that injury to the intima is a fav. oring factor only. He realized that the operation was rendered nore difficult and retarded by lim. iting the sutures to the two outer coats of the 
artery wall, so he passed his stitches through the whole thickness with perfectly satisfactory results. Those who opposed this suture through all three coats did so trom fear that the foreign substance in the vessel would cause endarteritis and thrombosis, that the injury to the endothelium necessarily caused by the sutures would interfere with the healing of the intima, and that bleeding might easily occur through the stitch holes, which might be enlarged by an increase in the blood pressure. Dörtler found that these fears were practically without foundation. In sixteen artery sutures which he did twelve included the intima and four only the adventitia and media. In one of each a thrombus formed. These were the first two experiments he did and the clot formation was due to faulty technique. He collected from various sources forty-three experiments where the intima was included in the suture, with thrombus formation in but five, and these tive failures were said not to be due to the method itself, and, furthermore, there have been five entirely successful cases in men where all the coats were included, without any thrombus formation. After tive to eight weeks nothing is to be seen of the sutures, and a thickening of the artery wall with a slight prominence of the intima alone indicates their position. The advantages of the suture through all the coats are its easy application, its adaptability to thin-walled vessels, and the certainty that the suture passes deep enough not to tear out, as might happen if one were trying to include only the two outer coats. He considers that very fine silk is the best suture material.

Jacobsthal hardened some of Dörfler's specimens and examined them microscopically. He found that the wound separation of the vessel wall is tilled with blood and fibrin which extend into the perivascular tissue. In a few days a thickening of the endothelium occurs, which surrounds the sutures and shuts them off from the lumen of the vessel. Soon a new growth of cells and blood vessels forces its way into the blood clot, which becomes more or less organized. From this comes a cellular growth end-mesoperiarteritis. Next, a retrograde process appears, in which the cells decrease in number, with fibres between them, and become poorer in protoplasm. The growth in the adventitia and media is principally connective tissue, with rarely some elastic elements, while in the intima the now growth is exceptionally rich in tine elastic lamellæ and fibres, which may go on to the formation of a sort of second elastica in the neighborhood of the scar. The sutures lying in the lumen are entirely shut off by the thickening of the intima and covered by endothelium. In the adventitia they become surrounded by granulation tissue and giant cells. There is no formation of new muscle fibres.

'The work up to this point of repairing an injury to an artery has been carried on without any mechanical aids. In 1894, however, Abbé oarried out some experiments, inserting glass tubes into the arteries. After finding the tube plugged by a clot in his first case, the circulation having been carried on by the collateral branches, he put one into the aorta of a cat, thinking that there the collateral circulation would not be sufficient if the tube became plugged. He showed the cat four months later at a medical meeting, feeling sure that the tube and aorta were patent. In 1900 Payr published an account of two new methods in which mechanical devices play an important part, similar to that of the Murphy button in intestinal anastomosis. He says that his experimental results have been satisfactory, but fails to describe any of them. For the first method

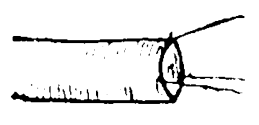

Fia. 1.

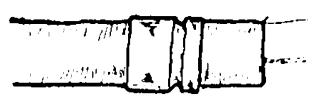

Fia. 3.

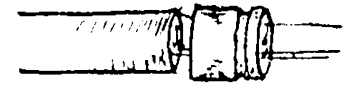

Fra. 2.

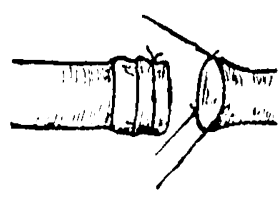

Fia. 4.

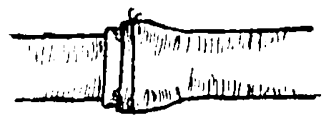

Fra. 5.

Payr'b Firat Metuod.

Fulis. 1, 2, 3, 4. Succeoding steps in operation. Fig. 5. Completed anastomosis.

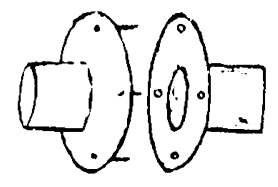

Fio. 1.

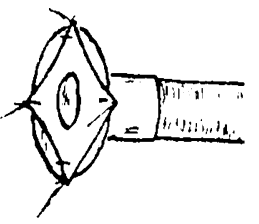

FIO. \&.

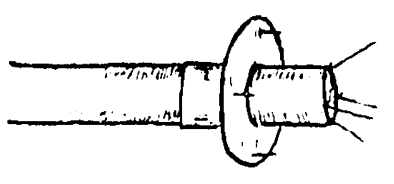

Fia. 2.

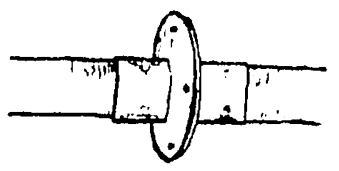

FIa. 4.
Fige. 1. Male and female cylinders. Fig. 2,3. Steps in operation. FIG. 4. Completed anastomusis.

a cylinder with a groove near one end is necessary. Through this the proximal end of the artery is drawn by pulling on sutures passed through its end. The vessel is then turned back over the cylinder and held by a ligature fitting into the groove. The distal end of the artery is then stretched by means of sutures in its end and pulled over the proximal end and the cylinder. Another ligature holds this in place. Thus intima is brought into contact with intima. For his second method he uses a male and female cylinder, the male having four pegs and the female four holes. The end of the artery is drawn 
through the male cylinder and pulled out so that it is caught on the pegs, the intima being thus turned out. The peripheral end is then drawn through the female cylinder and pulled out in a similar way, so that when the two cylinders are joined the intima of one end is fastened against the intima of the other. The cylinders in both methods are made of magnesium, which was found to be absorbed in a short time.

There are a few points about the technique of any repair operation on an artery which are almost self-evident, but might be overlooked unless one had thought about this branch of surgery. In the first place, absolute asepsis is necessary, for any infection about the wound makes the likelihood of thrombus formation the greater. The circulation must be controlled sufficiently far away from the injury to give room to work, and especially far away if a resection is to be done, for an artery when cut across retracts a long way. The circulation may be controlled by clamps armed with rubber, instruments made for this particular purpose, bands of gauze or the finger. No matter what means is used it must be with the slightest pressure possible, to prevent any more bruising than necessary. The vessel wall must be handled as little as possible. The suture must just fill the hole made by the needle, and both needle and suture must be the finest that can be handled. All clots must be wiped from the wound in the artery. A continuous suture is recommended because it minimizes the handling, and is quicker than an interrupted one, and because it always leaves a thread with which to hold the vessel wall away from the opposite one that a stitch may not include both. After the suture is com. plete the compression must be taken first from the distal end of the artery. This will let the blood flow back and test the suture before allowing the full blood pressure against the stitches by taking off all compression. If there is any real bleeding the circulation can be again controlled and more stitches put in. If there is only an ooze it can be stopped by gauze pressure for a moment or two. Suturing the sheath of the vessel is recommended, not so much because it strengthens the artery wall, as because it makes a barrier to any sepsis which may occur in the superficial part of the wound.

The field for the suture of arteries is necessarily rather small. It is suitable only when the vessel walls are healthy, and would be of no use in calcified arteries or a secondary hemorrhage where the vessel is bathed in pus. It is particularly serviceable in wounds of large arteries, such as the femoral or brachial, where a sudden tying of the vessel might possibly cause gangrene. The most favorable cases are those where the wound is made at the time of an operation. However, any clean cut wound can be sutured and ragged ones resected, if not involving too great a length. This suturing of arteries is adaptable to the treatment of traumatic and dissecting aneurisms.

The prognosis seems to be fairly good, though of course the procedure is still in its infancy.
Even if the suture itself is a failure through obliteration of the lumen, the operation may still be a success as far as the object for which it was undertaken is concerned, for as the closure of the vessel is slow, the collateral circulation has time to adapt itself to the new strain. There seems to be no danger of a bit of clot being washed away by the blood stream from the line of suture and causing trouble farther on, for in none of the cases or experiments was anything of this sort found, and as many of them were on the carotids a cerebral embolism with symptoms would certainly have occurred. The danger of the formation of an aneurism at the site of the suture seems to be slight, none having occurred in either experiments or actual cases. The longest experiment lasted, however, but 100 days, and in a 37 day old femoral suture there was a little out swelling, but not really enough to be called an aneurism, and it was considered probably due to the retraction of the scar in the surrounding tissues.

I have been able to collect up to the present date twenty recent operations on arteries, which I will brietly mention to show the practical value of this procedure :

1. Durante, 1882. Tibial artery wounded during romoval of chrondrosarcoma; catgut sutures through adventitia and media. Next year amputation for recurrence. Artery then found without any change except a narrowing at site of suture.

2. Durante, 1892. Amputation breast; axillary artery woundod; catgut sutures.

3. Rosa, 1892. Suture of wound in brachial $7 \mathrm{~mm}$. long, including only two outer coats.

4. Heidenhain, 1894. Wound of axillary artery while dissecting glands in axilla; catgut sutures.

5. v. Zoege Manteuffol, 1805. Wound of femoral while operating on arteriovenous aneurism; sutured. 6. Israol, 1895. Common iliac injured during a perityphilitic operation; silk sutures through all layers.

7. Ssabaujeff, 1896. Embolus in femoral artery from ulcerative endocarditis; gangrene threatened. An attempt was made to remove the embolus, but patient too weak to permit Ssabaujeff to carry out his whole plan. The artery, however, was opened and sutured. Nineteon days later patient died from the endocarditis and a spindle thrombus was found along the opening in tho intima.

8. Orlow, 1806. Wound in popliteal artery sutured through all the layers; additional stitches through adventitia and connective tissue; amputation later, when artery found patent but narrowed.

0. Murphy, 1897. Bullet wound of thigh; two small aneurismal sacs of femoral; one-half inch of femoral artery resected; proximal end invaginated into distal, the adventitia having been peeled off proximal; after the invagination it was pulled down over the line of suture and fastened there; the suture also of femoral vein.

10. Iindner, 1888. Femoral artery wounded during an operation for intestinal resection; suture with silk through all the coats; safety stitch through the adventitia.

11. Garré, 1888. Internal carotid injured during removal of cancerous glands; silk sutures through adventitia and media.

12. Garré, 1808. Wound of upper arm day before entrance to the hospital; wound of brachial artery sutured through all coats. After operation pulse and color returned to hand, which before had been pulseless and cyanotic.

13. Gérard Marchant, 1898. Arterial suture of humeral for arteriovenous aneurism. Doubtful result. 
14. Richard, 1899. Axillary artery wounded during oporation on axilla; catyut sutures.

15. Cammagrio, 18\%9. Wound of fomoral artery; suture through all the coats.

16. Kiimmall, 1900. Four to fivo centimetres of femorial artery resected, becanse involved in cancerous growth; proximal end invaginated into distal.

17. Soggel, 1900. Artery wounded in neck by wouldbo suicide; silk sutures through adventitia and media; jugular vein also sutured.

18, 19. Pacha, a Russian, is reported to havo done two cases by tho Murphy method on tho axillary artery. ${ }^{2}$

20. Peugnioz. Suturo of artery for arterioventus aneurism. I could not get tho journal in which this articlo was published, and therefore can give but the title.

When Dr. Lund spoke to me about writing this paper, I at first was tempted to decline, realizing that anything new which I might have to say should be supported by many experiments; but later, I felt that collecting and bringing up to date the literature of the subject might possibly not be without interest and might serve to awaken some discussion. I was glad of the chance to read a paper of this sort for another reason, that I might have an opportunity to urge upon those in charge of the new medical school the great need in Boston of a proper place in which to carry on such original experiments as are necessary in a subject of this sort.

Last spring I became interested in this branch of surgery, and, after having thought about it for awhile, decided that possibly I might add a little to its advance. 'To do this, many experiments should be carried ont. At present there is no opportunity for such work either at the Harvard Medical School or the bospital laboratories in Boston. Finally, I got a chance to work at one of the veterinary hospitals in the city, where the surgeons were most kind and thoughtful. The opportunity for aseptic work was, however, very slight, and the expense of leeping a number of dogs would have amounted to so much that $I$ was forced to give up all my schemes. I sincerely hope that accommodations for such work will be made in the new school, that Boston may not be behind in the advance of experimental surgery.

I hoped to show by experimentation that transplantation of arteries was possible, for if an artery can be entirely divided and then sutured successfully, why can it not be stitched to another tiunk? 'To accomplish this a lateral implantation would be necessary. If this proved possible, I had an idea that possibly in a certain number of abdominal ancurisms this procedure might be of some value.

Dr. Jones was kind enough to help me with the few experiments I did. As the technique of artery suture seemed rather hard, we started in on a simple operation.

I. Large black log.-- Right carotid dissected free. Circulation controlled by bands of gauze pulled about the artery and held tight by hemostatics. $A$ longitudinal incision of about one-third of an inch was male in the artery. The incision was closed hy tine silk interrupted sutures. Loos-

: Bougló. Bull. ot móm. Soc. Anal. do l'aris, 1900.. ening the distal gauze showed a leak in the suture line. The gauze was tightened again and another stitch put in. This procedure had to be repeated again before the leaking was controlled. There was still a little oozing, which entirely stopped after compression. The blood then passed freely though the sutures seemed slightly to constrict tho vessel.

A week later we killed the dog by trying to tie a glass tube in to his aorta. The carotid was found somewhat adherent to the surrounding structures. The stitches were scarcely discernible on the inside of the vessel. 'There appeared to be a very small parictal thrombus at one end of the cut, and there was a thread of what seemed like fibrin free in the lumen. The calibre of the vessel did not seem to be altered.

II. Irish terier. - Left carotid was dissected free and divided between two ligatures. Circulation was controlled by gauze bands as before. Longitudinal cut was made in each end and the corresponding edges were sutured with silk. When the distal gauze was loosened there was some leaking which was controlled by two more sutures. When both controlling gauzes were taken off there was no leaking. The pulsation proximal to the anastomosis was strong, distal to it weak, but distinct. 'The soft parts were joined by one stitch over the anastomosis. Five days later a more or less broken-down blood clot was let out.

Two weeks after the operation the dog was lilled with chloroform. The carotid was dissected out. About the site of the suture there was a large fusiform nass, apparently an organized blood clot. Air could be forced through the anastomosis without any leakage. On section, the ends of the two portions of the artery at the anastomosis were filled with a soft blood clot. Although the air had passed freely, it was possible to find only a connection big enough to admit a hair.

III. A week before the dog was killed we did a similar operation on the left carotid, only in this case cutting out a portion of the artery wall, that the opening at the anastomosis might be larger. After the operation the pulsation distal to the anastomosis was stronger than it had been on the right, where only slits had been made in the artery, but still weaker than on the proximal side of the anastomosis.

When the $\mathrm{dog}$ was killed this specimen was a week old. As he died, there was a secondary hemorliage. On dissection it was found that a stitch had given way. A clot was in the hole and extended into the artery. When this was removed a probe could be passed freely through the anastomosis.

My apology for prosenting such imperfect results is the firm belief that if they can be obtained under tho circumstances in which we worked, perfect ones can be reached when aseptic work is carried ont. I trust that someone who has the opportunity will go on with this branch of surgery, for it certainly has a definite field of usefulness. 


\section{LITERATURE.}

Lindner. Berl. klin. Woch., 1898.

Bouglé. Bull. et mém. Soc. Anat. de Paris, 1900, S. 6, v. II. Gérard Marchaut. Bull. ot métn Soc. de Chir., 1898.

Richurd. Bull. et mém. Soc. de Chir., 18!!y.

(8).

Jaboulay et Brian. Lyon Medical journal, 18!16, Ixxxi. Fossataro. Anuali di Medicina Navale Roma, March, 1901.

Peugniez. Gaz. med. de Picardle, 1900, xvili.

Murplyy. Medical Record, Jan. 16, 1897.

Kummell. Beitr. z. klin. Chir., 1900.

Dörtler. Beitr. z. klin. Chir., xxv, H. 3.

Jacobsthal. Beitr. z. klin. Chir., xxvii.

Payr. Arch. 1. klin. Chir, 1900, H. 1.

Heidenhain. Centrbl. f. Chir., 18!5, No. 49.

Abbe. New York Medical Journal, Jan. 13, 1894.

Jassinowsky. Arch. 1. klin. Chir., 1891, p. 4.2.

Seggel. Munch. med. Woch., Aug. 2, 1900.

\section{A CONTRIBUTION TO THE STUDY OF CAT- GUT AS A SUTURE AND LIGATURE MA- TERIAL.1}

BY IUGH CABOT, M.D., BOB'TON.

Tuk extent to which absorbable suture materials have como into general use makes it of the first importance that we should have quite detinite ideas in regard to the position which they hold as compared with the unabsorbable materials. The question of sterilization has called forth much able and thorough investigation, and upon it, at the present time, investigators are substantially in accord. It is, I think, generally accepted as proved that, by a considerable variety of methods, animal materials can be rendered sterile, and that danger of infection from their use is almost nil, or perhaps as nearly so as with any material at our command. While the question of sterilization has been closely studied, less atten. tion has been paid to the behavior of these materials in the tissues, and little is known of their durability and of the length of time during which they retain sutficient strength adequately to hold the tissues in apposition. 'I'he views of surgeons differ widely in regard to the length of time dur-ing which their suture materials remain strong, and there is surprisingly little experimental evidence to be found upun this point. In view of this unsatisfactory dearth of information, the writer undertook an investigation to determine if possible the length of time during which catgut of various sizes and makes and of different methods of preparation retains its strength in the tissues.

It will, I think, be generally admitted that it is desirable that a suture material retain its strength for three weeks, and it is obviously unwise to use absorbable materials which are retained in the tissues much longer than is positively necessary. What we want in an absorbable material is that it shall remain strong for three weeks and then disappear as fast as possible, for where these materials are retained in the tissues for a great length of time, they are open to many of the same objections as the unabsorbable materials. We not very infrequently see catgut and animal tendon sutures

1 Read before the Surgical Section of the Suffolk District MedIcal Society, Jan. 8, 1902 . discharged through sinuses, showing that lhey have become foreign bodies, and that their ab. surption has been too slow to counterbalance the tendency of the tissues to sequestrate foreign material.

The process of absorption of catgut tales place by infiltration with round cells and polynuclear leucocytes, and the rapidity of the process depends largely upon the blood supply of the part. In tissues of poor blood supply and consequent low vitality, as subcutaneous tissues and fascia, the rapidity of infiltration is much diminished and absorption is therefore markedly slower, while in very vascular tissues the most rapid absorption takes place. These facts should be borne in mind in estimating the true durability of absorbable materials.

\section{METHODS OF INVESTIGATION.}

In order to arrive as nearly as possible at uniform results, animals of the same variety have been used in all experiments, and sutures have been placed in an anatomically similar position. Rabbits were chosen because of their marlied ability to withstand infection from the pyogenic organisms and on account of the ease will which they can be handled. For the benefit of our antivivisection firiends, it may be here stated that all animals were completely etherized during the operation and were treated as surgical patients. All sutures were placed deep in the nuscles of the hind leg, a region of free blood supply where absorption would be as rapid as in any part of the body, and were so arranged as to include a considerable bundle of muscular filses and to be covered above and below by muscular planes. In order to have pieces of sufficient length to test their strength when removed, the gut was passed twice around the muscle selected and then linotted with the ends leftlong. The skin was closed with fine silk and a collodion dressing applied. Immunity from anything more than a mild sain inrection was very marked, and in only three cases rid any pus formation vecur about the sutures. The materials used were plain catgut in sizes Nos. 0,1 and 2, from maners Lee, l'ean, Leavens, Van Horn and Countie. Chromicized calgut in the same sizes and from the samo makers was also used.

\section{RESULTS.}

Briefly stated, the results were as follows:

Plain catgut. - Prepared by heating under pressure in alcohol, a method very generally employed in the moist preparations. The strength of these materials when removed was estimated by an attempt to break them. When they could not be broken in short lengths of one and onehalf to two inches, they were considered of full strength; when broken only with difficulty they were considered of good strength; when broken easily, worthless. No. 0 , good strength at four weeks (two cases); No. 1, full strength four to six weeks (seven cases); No. 1, prepared by dry heat, nearly absorbed in three weeks (two cases); 